\title{
Utilization of Electronic-resources by the postgraduate students, research scholars and faculty members of Indian Institute of Technology, Kharagpur
}

\author{
Ram Gopal Garg, Amit Kumar Tamrakar* \\ Department of Library and Information Science, SOS Jiwaji University, Gwalior, Madhya Pradesh, India
}

\begin{abstract}
This paper aims to evaluate the use of Electronic resources (E-resources) by the library users of Indian Institute of Technology, Kharagpur, India, with a view to examine the exposure of users to e-resources. Besides, it aims to highlight the alert services offered by the library, most preferred format of the journals, awareness of E-resources, helpfulness of e-resources and efforts made by the library for better E-services to their users. This study is based on a structured questionnaire; for the purpose of this study, total 822 questionnaires were distributed among the post graduate students, research scholars and faculty members. Of all distributed questionnaires, 412 questionnaires received back duly filled by the respondents. Various statistical methods have been used for analysis of data. The result of this study is presented and discussed in this paper.
\end{abstract}

Keywords: Electronic resources, India, Indian institute of technology, Kharagpur, use of electronic resources

\section{INTRODUCTION}

The rapid advancement of information and communication technology has brought a revolutionary change in the information scenario and gives rise to a number of options to handle varied information sources conveniently and effortlessly. Electronic resources (E-resources) have become the most sought after modern library's reserves in satisfying varied needs of students, teachers, and researchers with minimum risk and time. ${ }^{[1]}$ Information technology has changed the world and has become one of the important tools for retrieving information. The electronic information resources have acquired a major portion of library collections. The value and use of information resources, particularly E-resources, have

*Address for correspondence:

E-mail: amit_t1981@yahoo.co.in

\begin{tabular}{|l|l|}
\hline \multicolumn{2}{|c|}{ Access this article online } \\
\hline Quick Response Code: & \\
\hline & Website: \\
\hline & www.jscires.org \\
\cline { 2 - 3 } & \\
\hline DOI: & $10.4103 / 2320-0057.145621$ \\
\hline
\end{tabular}

J Scientometric Res. | May-Aug 2014 | Vol 3 | Issue 2 increased with the time. Therefore, there is necessity to make study on the different aspects of resources and the issues relating to the use of E-resources by users, more particularly by the faculty members of academic institutions. ${ }^{[2]}$

\section{LITERATURE REVIEW}

Several studies on use of E-resources by students, research scholars, and other professionals of various institutions have been carried out all over the world. Appleton in his study, perceptions on electronic library resources in further education, has expressed personal experiences on the use of E-resources and their impact on teaching and learning activity. ${ }^{[3]}$ Haridassan and Khan in their study, "impact and use of E-resources by social scientists in National Social Science Documentation Center (NASSDOC), India," have identified the acceptance of E-resources in the NASSDOC library in New Delhi, and determined their usage, performance, degree of user satisfaction, and barriers faced in the access of E-resources. ${ }^{[4]}$ Sutradhar described that how the Central Library, Indian Institute of Technology (IIT), Kharagpur has been changing its direction from traditional library to electronic library and now again it is moving toward digital library. ${ }^{[5]} \mathrm{He}$ also 
discussed various digital resources available in the library and focused three different aspect of creating standard digital library, one is converting the analogue resources to digital form, other one is metadata harvesting after converting print documents by applying dublin core metadata (SOS Jiwaji University, Gwalior, Madhya Pradesh, India) and last one is preservation of digital resources. Satpathy and Rout assessed and evaluated the use of E-resources by the faculty members of C.V. Raman College of Engineering, Bhubaneswar, with a view to examine the exposure of faculty members to E-resources. Besides, highlighted the problems encountered by the users and suggests some remedial measures for its improvement. ${ }^{[2]}$ Mounissamy and Rani in their study, "Evaluation of usage and usability of electronic journals (E-journals)," have identified the usage and usability of E-journals by the users of the NIT, Tiruchirapalli. ${ }^{[6]}$ Nikam and Pramodini in their study, "use of E-journals and databases (subscribed by UGC-Infonet consortium) by the University of Mysore: A survey" have analyzed the utilization of E-resources and the satisfaction levels of users of Mysore University. ${ }^{[7]}$ Nishy and Chand examined the changing face of libraries, particularly with regard to the journal subscription from print to electronic form through formation of consortia. ${ }^{[8]}$ They also discussed the benefits accrued to the library and information system of CSIR Laboratories owing to formation of a consortium to access E-resources.

\section{OBJECTIVES OF THE STUDY}

The objectives of the study are:

- To assess the contemporary use of electronic information resources by the users

- To examine the attitude of the users towards use of E-resources

- To find out the main reason(s) behind the usage of E-resources by them

- To suggest measures for improving the existing library system and services of Central Library

- To know the eminence of E-services provided by the library.

\section{METHODOLOGY}

This study is based on the survey (questionnaire) method. A structured questionnaire was designed to collect the data from the PG students, research scholars and faculty members studying/working in the various Departments of IIT, Kharagpur. Keeping in mind, the basic objectives of this study, the data were also personally collected from the aforesaid users. Beside, personal interviews were also conducted with library and information professionals to assess the relevant information. The population (target group) is too large for the research to attempt all of its members. Hence based on information requirement the sample has been selected from ten following departments exist in the IIT, Kharagpur.

- Department of Biotechnology

- Department of Chemical Engineering

- Department of Chemistry

- Department of Civil Engineering

- Department of Electrical Engineering

- Department of Electronics and Computer Engineering

- Department of Humanities and Social Sciences

- Department of Mathematics

- Department of Mechanical and Industrial Engineering

- Department of Physics.

For the purpose of this study, 822 questionnaires were distributed among the PG students, research scholars and faculty members. Of all distributed questionnaires, 412 questionnaires received back duly filled by the respondents in which 189 respondents were PG students, 152 research scholars and 71 faculty members. The data collected through the questionnaires was scrutinized, classified and tabulated for better understanding and clarity. Certain factors like whether the collected data are correct or incorrect, statistically true or not etc., judged using some statistical method.

\section{DATA ANALYSIS}

\section{Most Preferred Source in the Library}

Table 1 and Figure 1 show the results about most preferred source by the users in the library. The majority of the respondents 156 (37.85\%) preferred E-journals for their academic purpose. Simultaneously, a good number of respondents that is, $123(29.85 \%)$ preferred print journals. There are $80(19.41 \%)$ respondents also consult the back volumes of periodicals. On the other hand, the $40(09.70 \%)$ respondents preferred computerized database to fulfill their information need and $13(03.15 \%)$ respondents like to prefer other information sources such as educational CDs, cassettes, and e-books. It is noticed that E-journals is the first choice of the users followed by other resources.

\section{Most Preferred Format of the Journals by the Users}

Question posed to the three categories of user about "which format of a journal they like to prefer first for their 
Table 1: Most preferred source by the users in the library

\begin{tabular}{|c|c|c|c|c|c|c|}
\hline \multirow[t]{2}{*}{ User category } & \multicolumn{5}{|c|}{ Response (\%) } & \multirow[t]{2}{*}{ Total (\%) } \\
\hline & Print journals & Back volumes of periodicals & E-journals & Computerized database & Any other & \\
\hline PG students & $58(30.68)$ & $43(22.75)$ & $65(34.39)$ & $16(08.46)$ & $07(03.70)$ & $189(100)$ \\
\hline Research scholars & $47(30.92)$ & $25(16.44)$ & $59(38.81)$ & $18(11.84)$ & $03(01.97)$ & $152(100)$ \\
\hline Faculty members & $18(25.35)$ & $12(16.90)$ & $32(45.07)$ & $06(08.45)$ & $03(04.22)$ & $71(100)$ \\
\hline Total & $123(29.85)$ & $80(19.41)$ & $156(37.85)$ & $40(09.70)$ & $13(03.15)$ & $412(100)$ \\
\hline
\end{tabular}

E-journals $=$ Electronic journals

Table 2: Most preferred format of the journals by the users

\begin{tabular}{lcccc}
\hline User category & \multicolumn{3}{c}{ Response (\%) } & Total (\%) \\
\cline { 2 - 4 } & $\begin{array}{c}\text { Print } \\
\text { format }\end{array}$ & E-format & $\begin{array}{c}\text { Both of } \\
\text { them }\end{array}$ \\
\hline PG students & $79(41.79)$ & $89(47.08)$ & $21(11.11)$ & $189(100)$ \\
Research scholars & $47(30.92)$ & $65(42.76)$ & $40(26.31)$ & $152(100)$ \\
Faculty members & $17(23.94)$ & $32(45.07)$ & $22(30.98)$ & $71(100)$ \\
Total & $143(34.70)$ & $186(45.15)$ & $83(20.14)$ & $412(100)$ \\
\hline
\end{tabular}

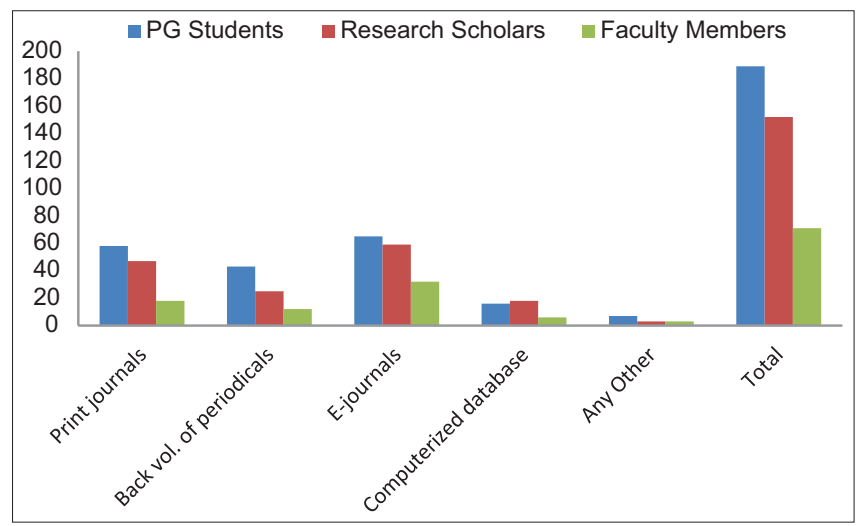

Figure 1: Most preferred source by the users in the library

study/research/teaching." Table 2 and Figure 2 analyze the data of respondents regarding their preference. The higher proportion of respondents $186(45.15 \%)$ indicated that they wish to get their desired information from the electronic version of the journals, similarly 143 (34.70\%) respondents preferred the print version of the journals and $83(20.14 \%)$ respondents pointed out that they give the same preference to the both electronic as well as print version to get their desired information.

\section{Frequency of the Use of Electronic Resources}

Table 3 and Figure 3 show the response of users about frequency of using E-resources in their relevant area. It is appeared from the analysis that $88(21.35 \%)$ respondents used the E-resources daily. However, 141 (34.22\%) respondents, have access to E-resources several times in a week. Apart from that, $142(34.46 \%)$ respondents may be termed occasional users of the E-resources. On the other hand, $41(09.95 \%)$ respondents have never access the E-resources. It is noted that during the survey period and due discussion with the users, due to tight academic/class schedule they don't have sufficient time to use the E-resources daily. In addition to aforesaid frequency of use, they also use the E-resources whenever need arises.

\section{Awareness about the Total Number of Electronic Resources Availability}

Data regarding user's awareness about the total number of E-resources available in the library is presented in Table 4 and Figure 4. It reveals that majority of the respondents $260(63.10 \%)$ have stated that they knows very well about what number of E-journals/database are available in the library concerned to their subject/discipline. Whereas, $152(36.89 \%)$ respondents specified that they do not know exactly about what number of E-journals/databases are available through the library.

\section{Ask about User's Need before Selection of Electronic Journals}

Table 5 and Figure 5 indicate the response regarding information need of the user's while selection of E-journals. In this connection, $217(52.66 \%)$ users responded that library mostly ask their information requirement related to different categories of subject/discipline before selection of E-journals for the library. Whereas, 85 (20.63\%) respondents reported that library rarely or never ask about their information needs before selection of E-journals. On the other hand, a large number of users as $110(26.69 \%)$ don't know about such this type of act happened or not in the library.

\section{Alert Services Provided by the Library}

Table 6 and Figure 6 reveal the response of the users regarding alert services about E-resources provided by the library. The highest proportion of respondents $236(57.28 \%)$ are stated that they are getting alert service continuously by the library. However, 65 (15.77\%) respondents pointed out that they did not getting 


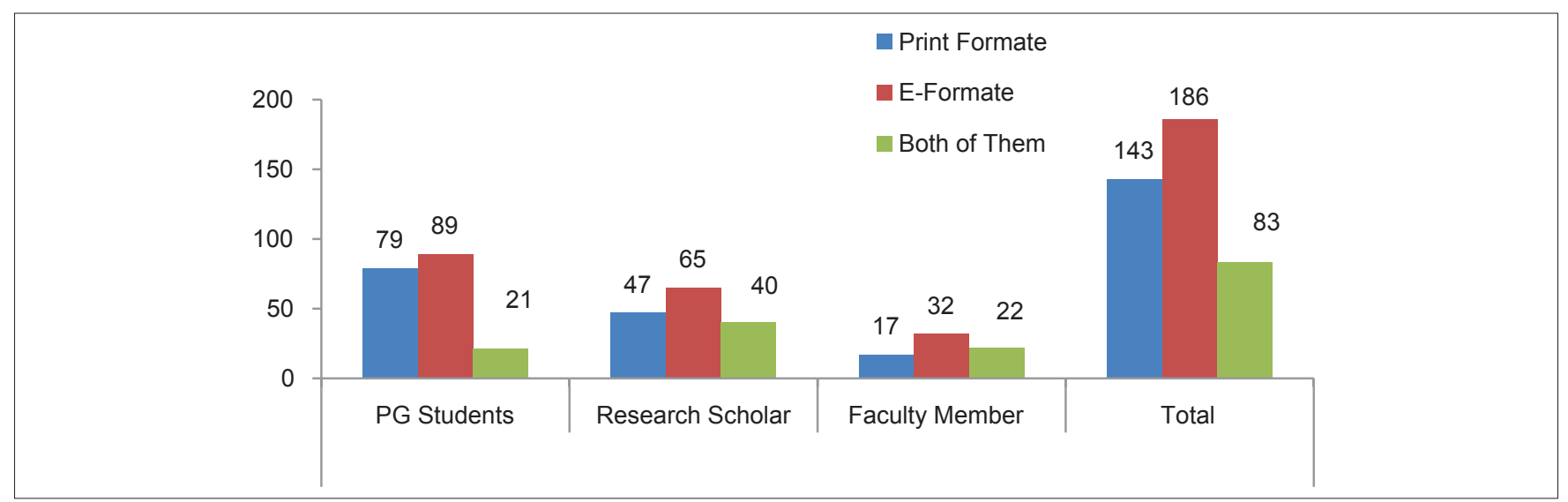

Figure 2: Most preffered formate of journals

Table 3: Frequency of the use of e-resources by the users

\begin{tabular}{|c|c|c|c|c|c|}
\hline \multirow[t]{2}{*}{ User category } & \multicolumn{4}{|c|}{ Response (\%) } & \multirow[t]{2}{*}{ Total (\%) } \\
\hline & Daily & Several time a week & Occasionally & Never & \\
\hline PG students & $42(22.22)$ & $51(26.98)$ & $76(40.21)$ & $20(10.58)$ & $189(100)$ \\
\hline Research scholars & $30(19.73)$ & $68(44.73)$ & $40(26.31)$ & $14(09.21)$ & $152(100)$ \\
\hline Faculty members & $16(22.53)$ & $22(30.98)$ & $26(36.61)$ & $07(09.85)$ & $71(100)$ \\
\hline Total & $88(21.35)$ & $141(34.22)$ & $142(34.46)$ & $41(09.95)$ & $412(100)$ \\
\hline
\end{tabular}

E-resources $=$ Electronic resources

Table 4: Awareness about the total number of e-resources availability

\begin{tabular}{lccc}
\hline User category & \multicolumn{2}{c}{ Response (\%) } & Total (\%) \\
\cline { 2 - 3 } & Yes & No & \\
\hline PG students & $100(52.91)$ & $89(47.08)$ & $189(100)$ \\
Research scholars & $98(64.47)$ & $54(35.52)$ & $152(100)$ \\
Faculty members & $62(87.32)$ & $09(12.67)$ & $71(100)$ \\
Total & $260(63.10)$ & $152(36.89)$ & $42(100)$ \\
\hline
\end{tabular}

E-resources $=$ Electronic resources

any alert services from the library about addition or deletion of E-resources in library collection. On the other hand, 111 (26.94\%) respondents did not respond in this regard.

Overall Quality of the E-services Provided by the Library

User's response regarding overall quality of the e-services provided by the library is depicted in Table 7 and Figure 7. It is appeared that, $167(40.53 \%)$ users have responded that e-services offered by the library are helpful for their work. Besides this 121 (29.36\%) respondents replied that services of the library are very helpful for their work. Apart from this, $88(21.35 \%)$ users are responded that overall qualities of library services are extremely helpful for their study/research/teaching. Although, a very small group of the users $36(08.73 \%)$ are not satisfied with the services provided by the library.

\section{RESULTS}

\section{Most Preferred Source in the Library}

The preponderance of the respondents $37.85 \%$ mostly preferred E-journals for their academic purpose, whereas $29.85 \%$ preferred print journals. There are 19.41\% respondents also consult the back volumes of periodicals. On the other hand, the $09.70 \%$ respondent's preferred computerized database to fulfill their information need and $03.15 \%$ respondents like to prefer other information sources such as educational CDs, cassettes, and e-books. It is appeared that E-journals are the first choice of the users followed by other resources.

\section{Most Preferred Format of the Journals}

The higher percentage of respondents $45.15 \%$ indicated that they wish to get their desired information from the electronic version of the journals, in the same way $34.70 \%$ respondents preferred the print version of the journals, on the other hand $20.14 \%$ respondents pointed out that they give the same preference to the both electronic as well as print version to get their desired information.

\section{Frequency of the Use of Electronic Resources}

It is come into sight from the analysis that $21.35 \%$ respondents used the E-resources daily. However 34.22\% 
respondents, have access to E-resources several times in a week. Apart from that, $34.46 \%$ respondents may be termed occasional users of the E-resources, whereas

Table 5: Ask about user's need before selection of E-journals

\begin{tabular}{lcccc}
\hline \multirow{2}{*}{ User category } & \multicolumn{3}{c}{ Response (\%) } & \multirow{2}{*}{ Total (\%) } \\
\cline { 2 - 5 } & Yes & No & I don't know & \\
\hline PG students & $94(49.73)$ & $50(26.45)$ & $45(23.80)$ & $189(100)$ \\
Research scholars & $72(47.36)$ & $27(17.76)$ & $53(34.86)$ & $152(100)$ \\
Faculty members & $51(71.83)$ & $08(11.26)$ & $12(16.90)$ & $71(100)$ \\
Total & $217(52.66)$ & $85(20.63)$ & $110(26.69)$ & $412(100)$ \\
\hline
\end{tabular}

E-journals=Electronic journals

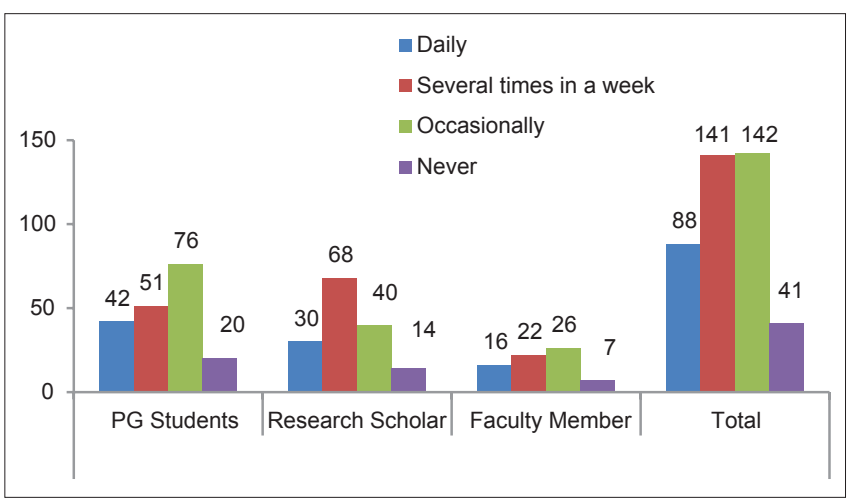

Figure 3: Frequency of use of electronic resources
$09.95 \%$ respondents have never access the E-resources. It is celebrated that during the survey period and due discussion with the users, due to tight academic/class schedule they don't have sufficient time to use the E-resources daily. In addition to aforesaid frequency of use, they also use the E-resources whenever need arises.

\section{Awareness about the Total Number of Electronic Resources}

It is reveals that majority of the respondents $63.10 \%$ have stated that they are fairly aware about the number of E-journals/database available in the library concerned to their subject/discipline. Although, 36.89\% respondents specified that they do not know exactly about what number of E-journals/databases are available through the library.

\section{Ask about User's Need before Selection of Electronic Journals}

After ascertaining the data we concluded that $52.66 \%$ users replied that, library mostly ask their information requirement related to different categories of subject/discipline before selection of E-journals for the library. Whereas, 20.63\% respondents reported that library rarely or never ask about

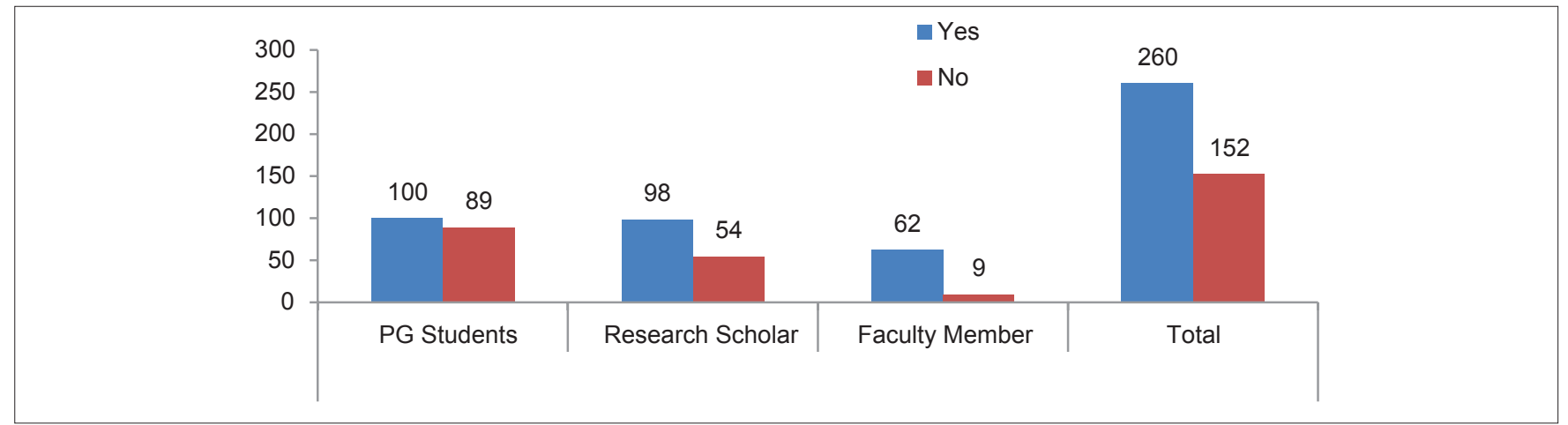

Figure 4: Awareness about number of electronic resources availability

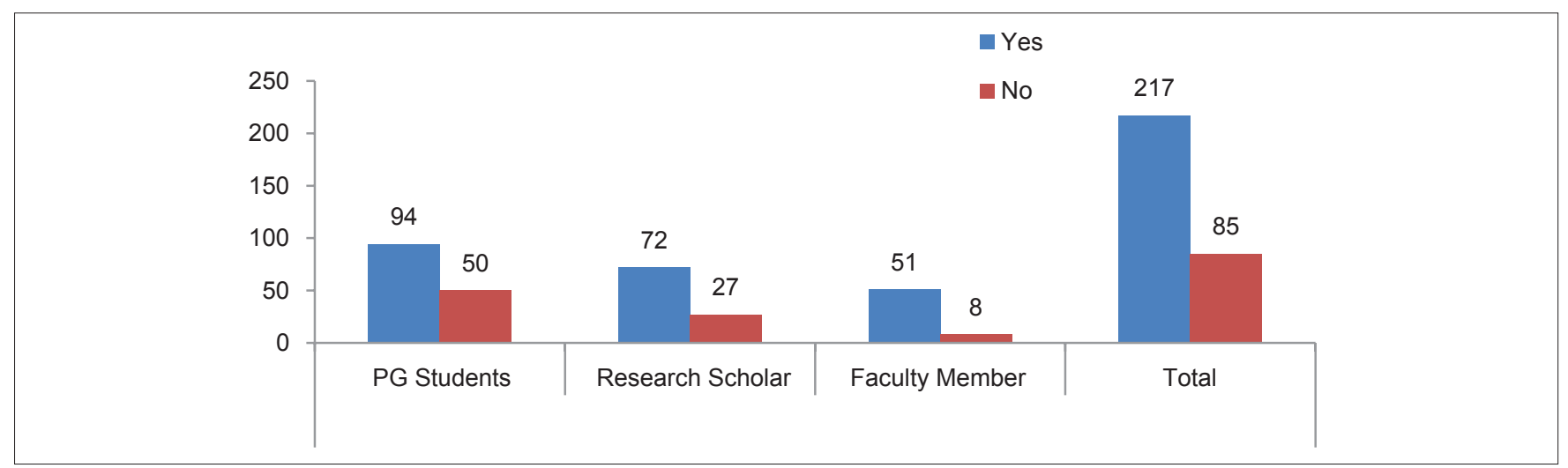

Figure 5: Ask about users need before selection of electronic journals 


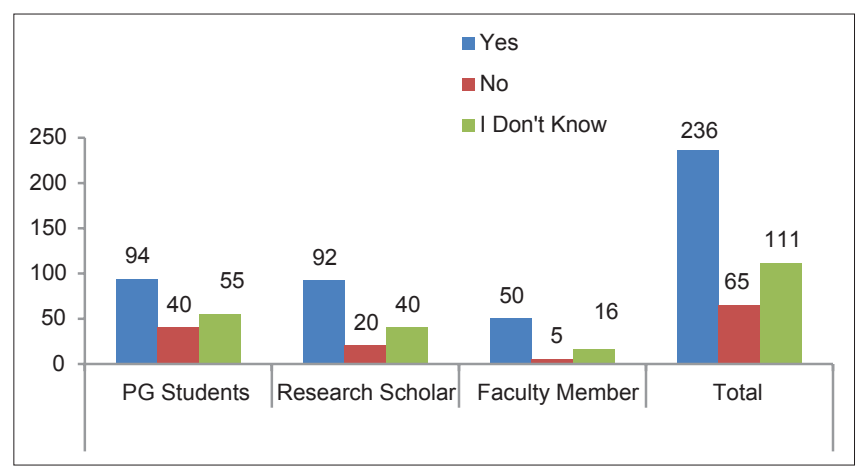

Figure 6: Alert services provided by the library

Table 6: Alert services provided by the library

\begin{tabular}{lcccc}
\hline \multirow{2}{*}{ User category } & \multicolumn{3}{c}{ Response (\%) } & \multirow{2}{*}{ Total (\%) } \\
\cline { 2 - 5 } & Yes & No & I don't know \\
\hline PG students & $94(49.93)$ & $40(21.16)$ & $55(29.10)$ & $189(100)$ \\
Research scholars & $92(60.52)$ & $20(13.15)$ & $40(26.31)$ & $152(100)$ \\
Faculty members & $50(70.42)$ & $05(07.04)$ & $16(22.53)$ & $71(100)$ \\
Total & $236(57.28)$ & $65(15.77)$ & $111(26.94)$ & $412(100)$ \\
\hline
\end{tabular}

Table 7: Overall quality of the e-services provided by the library

\begin{tabular}{lccccc}
\hline $\begin{array}{l}\text { User } \\
\text { category }\end{array}$ & \multicolumn{4}{c}{ Response (\%) } & Total (\%) \\
\cline { 2 - 4 } & Helpful & \multicolumn{2}{c}{$\begin{array}{l}\text { Very } \\
\text { helpful }\end{array}$} & $\begin{array}{c}\text { Extreme } \\
\text { helpful }\end{array}$ & $\begin{array}{c}\text { Not } \\
\text { helpful }\end{array}$ \\
\hline $\begin{array}{l}\text { PG } \\
\text { students }\end{array}$ & $85(44.97)$ & $46(24.33)$ & $38(20.10)$ & $20(09.17)$ & $189(100)$ \\
$\begin{array}{l}\text { Research } \\
\text { scholars }\end{array}$ & $62(40.78)$ & $50(32.89)$ & $28(18.42)$ & $12(07.89)$ & $152(100)$ \\
$\begin{array}{l}\text { Faculty } \\
\text { members }\end{array}$ & $20(28.16)$ & $25(35.21)$ & $22(30.98)$ & $04(05.63)$ & $71(100)$ \\
Total & $167(40.53)$ & $121(29.36)$ & $88(21.35)$ & $36(08.73)$ & $412(100)$ \\
\hline
\end{tabular}

their information needs before selection of E-journals. On the other side, a large number of users as $26.69 \%$ don't know about such this type of act happened or not in the library.

\section{Alert Services Provided by the Library}

A big amount of respondents $57.28 \%$ are stated that they are getting alert service continuously by the library. However, $15.77 \%$ respondents pointed out that they did not get any alert service from the library about addition or deletion of E-resources in library collection, whereas $26.94 \%$ respondents did not reply in this regard.

Overall Quality of the E-services Provided by the Library

Most of the users $40.53 \%$ replied that E-services offered by the library are helpful for their work. Besides this, $29.36 \%$ respondents replied that services of the library

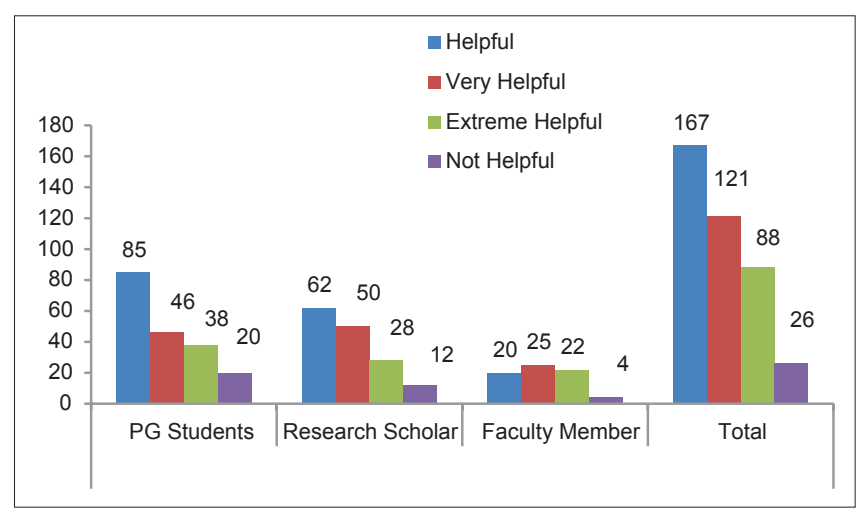

Figure 7: Over all qualities of library services

are very helpful for their work. Apart from this, 21.35\% users are responded that overall qualities of library services are extremely helpful for their study/research/teaching. Although a very small group of the users $08.73 \%$ are not satisfied with the services provided by the library.

\section{CONCLUSION}

The advantages of E-resources have drawn attention of the library users to a great extent. Users are heavily dependent on E-resources for their required information and to keep themselves up-to-date in their subject area. Though some expects that the role of libraries as a gateway to the E-resources will have less importance in future as users access more and more E-resources in their respective subjects, it seems to be more hypothetical. Rather the role of libraries in the age of E-resources will increase tremendously, particularly in providing training and guidance to use authentic and relevant information. The libraries are and will develop necessary tools to provide such services to their users satisfactorily. The study reveals that the all the three categories of the users of IIT, Kharagpur, are using the available E-resources satisfactorily. Simultaneously, the Central Library of IIT, Kharagpur is playing an important role in promotion, assistance and guidance in accessing the E-resources. Still there is enough scope for Central Library to aware their users about how number of E-resources is available in the library of particular subject area, and trained them to use the E-resources in better way.

\section{REFERENCES}

1. Verma N, Tamrakar R, Shrivastava M. Use of collection and service of TIRC of DRDE Gwalior. Libr Her 2007;45:265-82.

2. Satpathy SK, Rout B. Use of e-resources by the faculty members with special reference to CVRCE Bhubaneswar. DESIDOC J Libr Inf Technol 2010;30:11-6. 
3. Appelton L. Perceptions of electronic library resources in further education. Electron Libr 2006;24:619-34.

4. Haridassan S, Khan M. Impact and use of e-resources by social scientists in National social science documentation center. Electron Libr 2009;27:117-33.

5. Sutradhar B. Crating digital resources at IIT Kharagpur: A case study. TERI-International conference on digital libraries. New Delhi; 2004. p. 131-45. Available from: http://www.teriin.org/ library/services.htm. [Last accessed on 2012 May 17].

6. Mounissamy P, Rani BS. Evaluation of usage and usability of electronic journals. SRELS J Inf Manage 2005;42:189-205.

7. Nikam P, Pramodini B. Use of e-journals and databases by the academic community of university of Mysore: A survey. Ann Libr
Inf Stud 2007;5:19-22.

8. Nishy $P$, Chand $P$. Strengthening $R$ and $D$ information systems through library consortium: A case of CSIR laboratories. Ann Libr Inf Stud 2008;55:45-51.

How to cite this article: Garg RG, Tamrakar AK. Utilization of Electronic-resources by the postgraduate students, research scholars and faculty members of Indian Institute of Technology, Kharagpur. J Sci Res 2014;3:75-81.

Source of Support: Nil, Conflict of Interest: None declared

Announcement

\section{Android App}

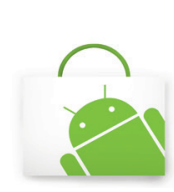

A free application to browse and search the journal's content is now available for Android based are stored on the device for future offline browsing. Internet connection is required to access the back issues and search facility. The application is compatible with all the versions of Android. The application can be downloaded from https://market.android.com/details?id=comm.app.medknow. For suggestions and comments do write back to us. 